\title{
Lively debate on disability insurance for medical students at CMA meeting
}

\author{
n Cite as: CMAJ 2017 September 11;189:E1167-8. doi: 10.1503/cmaj.1095488
}

Posted on cmajnews.com on Aug. 22, 2017.

W hat started as a call for a specific change to disability insurance programs for medical students turned into a lengthy debate about autonomy and policy details at the annual general council of the Canadian Medical Association (CMA). In the end, $62 \%$ of delegates voted against a motion for the CMA to support medical students getting disability insurance by default rather than having to choose their own coverage.

Dr. Janice Wong of BC, who put forward the motion, said that when students enter medical school, they are young and may feel infallible. But anything can happen during the decade of training ahead.
"Unforeseen circumstances may affect your ability to become the physician and person that you strive to be," said Wong.

For busy medical students, however, getting disability insurance may fall to the bottom of their to-do lists, said Wong. She noted that many provincial and territorial medical associations offer disability insurance to medical students, but they currently have to opt in. Doctors of $B C$ provides first-year medical students with coverage for free. Yet $10 \%$ of those students still don't sign up. Having default policies, which students could opt out of if they want, would provide a safety net, said Wong.

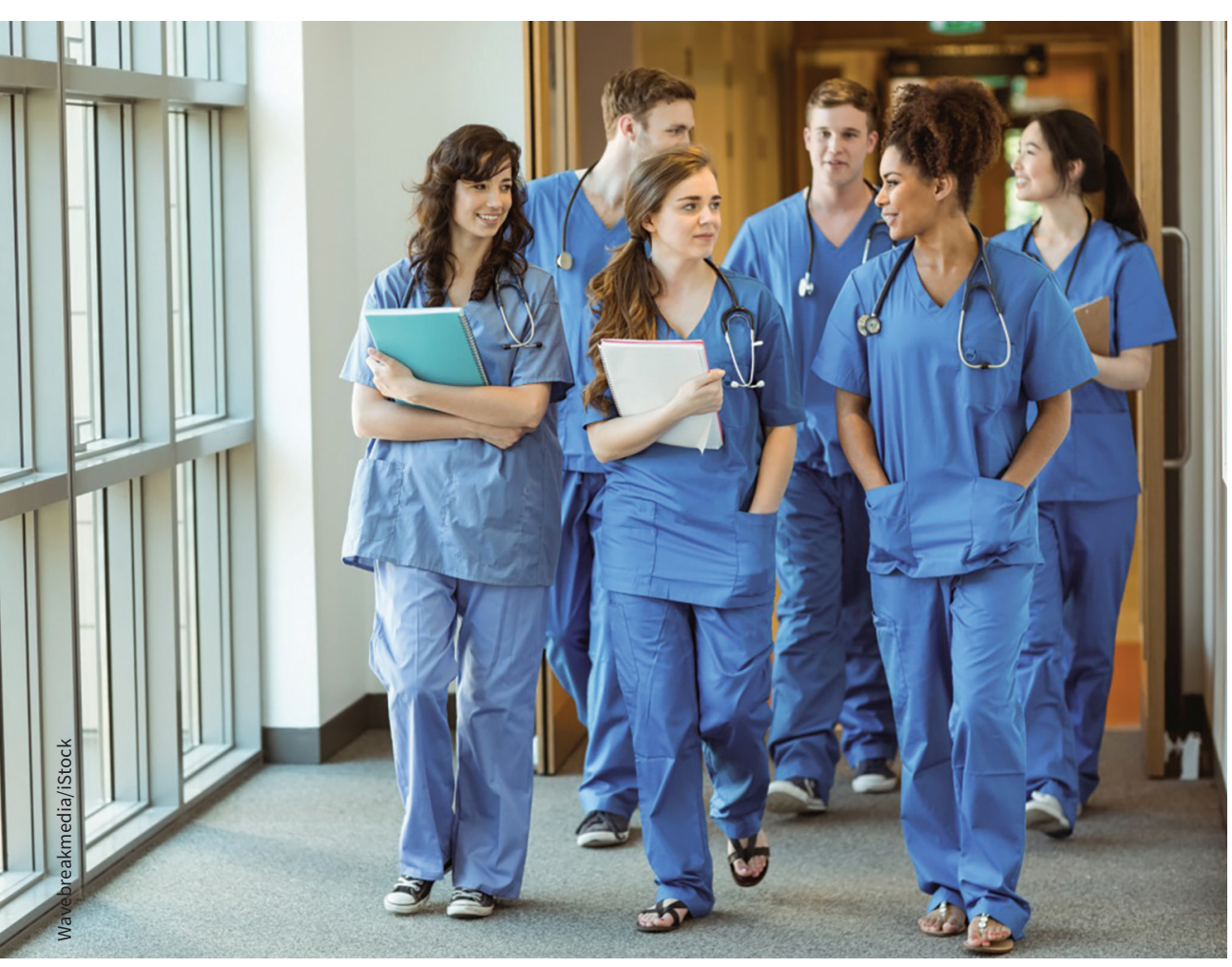

Students may enter medical school young and healthy but could suffer health problems over the course of their decade of training.
Dr. Ralph Jones of BC, who is a member of the insurance committee for Doctors of $\mathrm{BC}$, urged CMA members to support the motion. The $10 \%$ of students who don't obtain insurance are often those who need it most, he said. Perhaps they are too busy or flustered. They may already be ill.

"These are people already in trouble," said Jones. "This is the spirit behind this motion."

Despite the good intentions behind the motion, some physicians and medical students weren't convinced it was a good idea. Vivian $\mathrm{Ng}$, a medical student and cochair of the Ontario Medical Students Association, recalled her experience choosing disability insurance. The Ontario Medical Association (OMA) visited her class and explained all the available options and alternatives.

"We really appreciated that shared decision making, and I think having an opt-out policy takes away some of that autonomy that students really appreciate," said $\mathrm{Ng}$.

Several others at the session agreed with $\mathrm{Ng}$, suggesting that educating medical students about their choices, rather than forcing them to opt out of an imposed policy, was the better direction to take.

Dr. Franco Rizzuti, president of the Canadian Federation of Medical Students, stressed that the topic was very important to medical students. "We know disability insurance is a big, big issue," he said.

But he had a problem with the language, not the spirit, of the motion. Rather than focus on opting in or opting out, he said, the CMA should instead help ensure disability insurance for 
medical trainees is portable and transferable between provinces. Besides, he noted, in provinces such as Alberta, optout insurance policies violate provincial legislation.

Dr. Pamela Liao of Ontario, who is vice-president of the Canadian Association of Physicians with Disabilities, was concerned about the lack of details in the motion. She shared her experience with disability insurance, noting that she had been turned down because of a pre-exist- ing condition. A disability obtained during her medical training forced a change in career path, she said, so the topic was one very near to her.

"Though I wholeheartedly support the spirit of this motion, I find it problematic that some of the details that would have to be worked out afterwards could put people in a very vulnerable position if they are put into a disability program that doesn't necessarily accommodate their individual needs," said Liao.
Some of those who defended the motion suggested that focusing on details now was not the priority. It is far more important just to start a process that could eventually lead to all medical students in Canada being covered, said Dr. Barbara Blumenauer of BC. "The longer we delay this, inevitably somebody that would have been covered will not be covered and will end up disabled."

Roger Collier, CMAJ 